\title{
Sintering and mechanical properties of $\beta$-SiC powder obtained from waste tires
}

\author{
G. MAGNANI ${ }^{a,{ }^{*}}$, S. GALVAGNO ${ }^{b}$, G. $\mathrm{SICO}^{b}$, S. PORTOFINO ${ }^{b}$, \\ C. FREDA ${ }^{b}$, E. BURRESI ${ }^{c}$ \\ ${ }^{a}$ ENEA, SSPT-PROMAS-TEMAF, Faenza Research Laboratories, Via Ravegnana 186, 48018 Faenza (RA), Italy \\ ${ }^{b}$ ENEA, SSPT-PROMAS-NANO, Portici Research Center, P.le Enrico Fermi 1, 80055 Portici (NA), Italy \\ ${ }^{c}$ ENEA, SSPT-PROMAS-MATAS, Brindisi Research Center, S.S. 7 Appia km 706,00, 72100 Brindisi, Italy
}

Received: June 12, 2015; Revised: September 05, 2015; Accepted: September 14, 2015

(C) The Author(s) 2016. This article is published with open access at Springerlink.com

\begin{abstract}
Plasma synthesized SiC powder obtained from quartz and carbonaceous residue of waste tires was successfully sintered at $1925{ }^{\circ} \mathrm{C}$ by pressureless liquid-phase method using yttria and alumina as sintering aids (T-SiC). Comparison with sintered $\mathrm{SiC}$ obtained from commercial powder (C-SiC) put in evidence of similar sintered density (98\%T.D.), but much finer microstructure of T-SiC than that of $\mathrm{C}-\mathrm{SiC}$. T-SiC also showed higher flexural strength than $\mathrm{C}-\mathrm{SiC}$ both at room temperature (508 vs. $458 \mathrm{MPa})$ and at $1500{ }^{\circ} \mathrm{C}(280 \mathrm{vs.} 171 \mathrm{MPa})$. Difference in liquid phase was responsible for the differences in hardness and fracture toughness. The high value of the Young's modulus of T-SiC $(427 \mathrm{MPa})$ confirmed the high degree of sinterability of this powder and that it can be a promising candidate for structural applications with high added value.
\end{abstract}

Keywords: sintering; mechanical properties; $\mathrm{SiC}$; structural application

\section{Introduction}

Silicon carbide $(\mathrm{SiC})$ is one of the most widely used non-oxide ceramic materials for many industrial applications for both structural and electrical purposes. Superior properties, such as low bulk density, high strength, high hardness, high wear and thermal shock resistance, high oxidation and chemical resistance, and good semiconductivity, make $\mathrm{SiC}$ an excellent candidate for high power, high temperature electronic, high performance abrasive and cutting applications $[1,2]$.

To date, the cheapest and still most industrially used

\footnotetext{
* Corresponding author.

E-mail: giuseppe.magnani@enea.it
}

method to synthesize $\mathrm{SiC}$ powder is the carbothermal reduction of $\mathrm{SiO}_{2}$, also known as Acheson process [3]. Starting from inexpensive silica sand and low-ash petroleum coke carbon (or other carbon source), $\mathrm{SiO}_{2}-\mathrm{C}$ reaction occurs in a graphite electric resistance furnace at very high temperature (from 1400 up to $2700{ }^{\circ} \mathrm{C}$ ), leading to polycrystalline $\mathrm{SiC}$ varying in purity [3-5]. Depending on temperature, two main phases are possible: $\alpha-\mathrm{SiC}$, having hexagonal crystal structure, is the stable form at elevated temperature as high as $1700{ }^{\circ} \mathrm{C}$; $\beta$-SiC, having cubic zinc-blende structure, is formed at temperature below $1700{ }^{\circ} \mathrm{C}$.

In order to obtain high performance $\mathrm{SiC}$ ceramics, several alternative methods have hence been proposed for the synthesis of high purity and selected quality powder over the last decades. Among these, the most 
common methods are: physical vapor transport (PVT) technique, chemical vapor deposition (CVD), self-propagating high temperature synthesis (SHS), sol-gel, microwave, and plasma driven reactions [6-12]. In addition, special attention was given in recent years towards synthesis of nanosized $\mathrm{SiC}$ powder to allow the production of high performance products like structural components. Particularly, plasma techniques have been attractive for nanoscale synthesis due to the high energy available and the short reaction time required. Many examples could be found in literature using different types of precursors or plasma sources (i.e., transfer arc, $\mathrm{DC}$, or RF thermal plasma) [13-18]. Ultrapure $\beta-\mathrm{SiC}$ powder was successfully synthesized in RF-plasma systems from different types of precursors, such as silicon and $\mathrm{CH}_{4}[13,14]$, trichloromethyl silane [15], silicon monoxide and methane [16], chlorosilane and methane [17], organosilanes [18], and coarse $\mathrm{SiC}$ powder [19]. Furthermore, many efforts have been made to produce $\mathrm{SiC}$ and other technical ceramics from secondary raw materials like biomass residues (e.g., rice husk) and wastes [12,20-22]. In this last context, even more recently, plasma technique was applied for the synthesis of $\mathrm{SiC}$ powder using low cost silica and carbonaceous residue of tire pyrolysis as starting materials [23]. Although this process belongs to plasma synthesis methods, reaction between low cost silica and carbon source powder occurs similarly to the rapid carbothermal reduction but in a continuous process and resulting in submicronic powder mainly crystallized in $\beta$ phase.

In this work, sintering and characterization of sintered $\mathrm{SiC}$ from waste tires were carried out. In particular, pressureless liquid-phase sintering process was applied to $\mathrm{SiC}$ powder using yttria and alumina as sintering aids. In order to assess the quality of the obtained product for making components usable in industry, comparison with $\mathrm{SiC}$ commercial powder was then proposed. Microstructure and mechanical properties of sintered $\mathrm{SiC}$ samples were examined and discussed.

\section{Experimental procedure}

$\beta$-SiC powder from waste tires ( $\mathrm{T}-\mathrm{SiC}$ ) was synthesized following a process based on a plasma method using quartz sand and char from gasification of waste tires as silica and carbon sources, respectively. Synthesis and purification conditions are described elsewhere $[24,25]$.
In order to achieve high sintered density, yttria (4.1 wt\%) and alumina (5.2 $\mathrm{wt} \%$ ) were added to T-SiC powder as sintering aids, taking into account the residual alumina contained in the synthesized powder $(0.5 \mathrm{wt} \%)$. Mixing in ethanol was performed by Turbola mixer; then, the mixture was dried and sieved. Commercially available ready-to-press $\alpha$-SiC powder (C-SiC) for liquid-phase sintering with appropriate amounts of organic binder and sintering aids (SIKA Densitec-L, Saint Gobain, Norway) was used for comparison. The main characteristics of $\mathrm{T}-\mathrm{SiC}$ and $\mathrm{C}-\mathrm{SiC}$ powder are reported in Table 1.

Discs of both $\mathrm{T}-\mathrm{SiC}$ and $\mathrm{C}-\mathrm{SiC}$ with diameter of $40 \mathrm{~mm}$ and thickness of $3 \mathrm{~mm}$ were prepared by uniaxial pressing at $100 \mathrm{MPa}$ followed by cold isostatic pressing at $200 \mathrm{MPa}$. Sintering was performed in a graphite resistance high temperature furnace in flowing argon at $1 \mathrm{~atm}$. Sintering for T-SiC was conducted at $1925{ }^{\circ} \mathrm{C}$ for $0.5 \mathrm{~h}$, while for $\mathrm{C}-\mathrm{SiC}$ was done at $1930{ }^{\circ} \mathrm{C}$ for $1 \mathrm{~h}$. Both sintering processes were conducted without sintering bed.

Density of the samples was determined by the Archimedes method (ASTM C373). Polished and plasma etched $\left(70 \% \mathrm{CF}_{4}-30 \% \mathrm{O}_{2}\right)$ sintered $\mathrm{SiC}$ samples were observed using scanning electron microscopy (SEM; LEO 438-VP). X-ray diffraction (XRD) analysis was used to determine the qualitative composition in terms of crystalline phases of the sintered samples. $\mathrm{X}$-ray patterns were collected with a Philips powder diffractometer with a Bragg-Brentano geometry and equipped with a copper anode operated at $40 \mathrm{kV}$ and $30 \mathrm{~mA}$ (step $0.02^{\circ}$, time $6 \mathrm{~s}$ ). The phase analysis was carried out with the PC X'pert High Score software Version 2.2a (PANalytical B.V., Almelo, the Netherlands).

The flexural strength at room temperature, $1300{ }^{\circ} \mathrm{C}$, and $1500{ }^{\circ} \mathrm{C}$ was determined by four-point bending tests. Ten samples as bars with dimension of $2 \mathrm{~mm} \times 2.5 \mathrm{~mm} \times$ $25 \mathrm{~mm}$ were prepared and tested in accordance with the

Table 1 Physical and chemical characteristics of T-SiC and C-SiC

\begin{tabular}{|c|c|c|}
\hline Property & $\mathrm{T}-\mathrm{SiC}$ & $\mathrm{C}-\mathrm{SiC}$ \\
\hline Specific surface area $\left(\mathrm{m}^{2} / \mathrm{g}\right)$ & 31 & 13 \\
\hline Bulk density $\left(\mathrm{g} / \mathrm{cm}^{3}\right)$ & - & 0.86 \\
\hline Granule size $(\mu \mathrm{m})$ & 0.35 & 100 \\
\hline $\mathrm{Al}_{2} \mathrm{O}_{3}(\mathrm{wt} \%)$ & 5.7 & 5.5 \\
\hline $\mathrm{Y}_{2} \mathrm{O}_{3}(\mathrm{wt} \%)$ & 4.1 & 3.5 \\
\hline Aluminium (ppm) & 1410 & 1200 \\
\hline Oxygen (wt \%) & 1.2 & 0.75 \\
\hline Carbon (wt $\%)$ & $\max 0.5$ & 0.15 \\
\hline Organic binder (wt\%) & - & 6 \\
\hline
\end{tabular}


standard ENV 843-1 (crosshead speed $0.5 \mathrm{~mm} / \mathrm{min}$, support span $20 \mathrm{~mm}$ ).

Hardness and fracture toughness were determined by Vickers indentation method. Indentation load was set at 98 N. Fracture toughness was calculated using the following equation for the median crack [26]:

$$
K_{\mathrm{IC}}=0.203 H a^{1 / 2}(c / a)^{-3 / 2}
$$

where $H$ is the hardness; $a$ is the impression radius; and $c$ is the crack length.

The elastic modulus of the bars was determined by applying the impulse excitation method in accordance with the standard EN 843-2 using a frequency analyzer GrindoSonic System Mk5-Industrial (J.W. Lemmens N.V., Belgium). The values of Young's modulus were calculated in accordance with the following equation:

$$
E=0.946\left(m f^{2} / b\right)(l / h)^{3}\left[1+6.585(h / l)^{2}\right]
$$

where $E$ is the dynamic Young's modulus; $m$ the mass of the test piece; $b$ the width of the test piece perpendicular to the flexural mode vibration; $h$ the thickness of the test piece in direction of flexural vibration; $l$ the length of the test piece; and $f$ the fundamental frequency of flexural vibration.

\section{Results and discussion}

The SEM image of the starting T-SiC powder is shown in Fig. 1. The powder shows very fine particle size, typical of powder synthesized by plasma technique. In addition, particles show rounded morphology with a very low level of agglomeration which is not usual for powder with average particle size of $345 \mathrm{~nm}$ as T-SiC (Fig. 2).

Density, shrinkage, and weight loss after sintering for both $\mathrm{T}-\mathrm{SiC}$ and $\mathrm{C}-\mathrm{SiC}$ samples are reported in Table 2 (T.D. $=3.24 \mathrm{~g} / \mathrm{cm}^{3}$ ). As it can be seen, sintered density of T-SiC powder is identical to that of the commercial $\mathrm{SiC}$ powder. The higher shrinkage obtained for $\mathrm{T}-\mathrm{SiC}$ is essentially due to the lower green density. Furthermore,

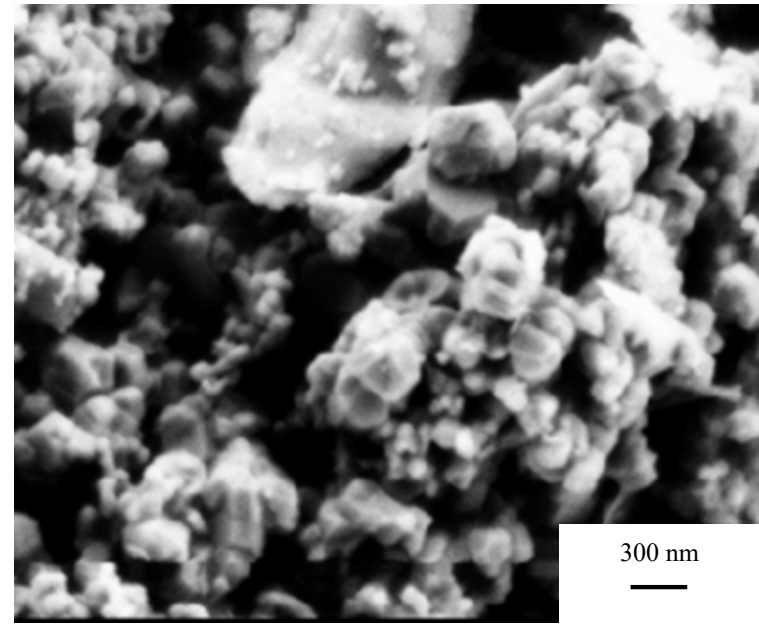

Fig. 1 SEM image of T-SiC powder.

Table 2 Density, shrinkage, and weight loss of T-SiC and $\mathrm{C}$-SiC ceramics

\begin{tabular}{lcc}
\hline \multicolumn{1}{c}{ Property } & T-SiC & C-SiC \\
\hline Green density (\%T.D.) & $47 \pm 0.2$ & $52 \pm 0.3$ \\
Sintered density (\%T.D.) & $98 \pm 0.2$ & $98 \pm 0.1$ \\
Shrinkage (\%) & $18 \pm 0.3$ & $16 \pm 0.3$ \\
Weight loss after sintering (\%) & 5.0 & 4.7 \\
\hline
\end{tabular}

the weight loss is due to the well-known reactions between silicon carbide and sintering additives with the formation of gaseous species:

$$
\begin{aligned}
\mathrm{SiC}(\mathrm{s}) & +\mathrm{Al}_{2} \mathrm{O}_{3}(\mathrm{~s}) \rightarrow \mathrm{Al}_{2} \mathrm{O}(\mathrm{g})+\mathrm{SiO}(\mathrm{s})+\mathrm{CO}(\mathrm{s}) \\
\mathrm{SiC}(\mathrm{s})+\mathrm{Y}_{2} \mathrm{O}_{3}(\mathrm{~s}) & \rightarrow \mathrm{Y}_{2} \mathrm{O}(\mathrm{g})+\mathrm{SiO}(\mathrm{s})+\mathrm{CO}(\mathrm{s})
\end{aligned}
$$

Thermodynamic evaluation of these reactions was previously performed by Baud et al. [27], confirming the formation of gaseous species in the temperature range of $1200-2300 \mathrm{~K}$. Microstructure of T-SiC and $\mathrm{C}-\mathrm{SiC}$ sintered samples is then shown in Fig. 3. Both samples display a very low residual porosity. Sintered $\mathrm{T}$-SiC exhibits much finer microstructure (average grain size $0.95 \mu \mathrm{m}$ ) than that obtained with the commercial $\mathrm{SiC}$ (average grain size $3.52 \mu \mathrm{m}$ ) as a consequence of the finer grain size of T-SiC powder than that of C-SiC. Nevertheless, some coarse grains are also detected as

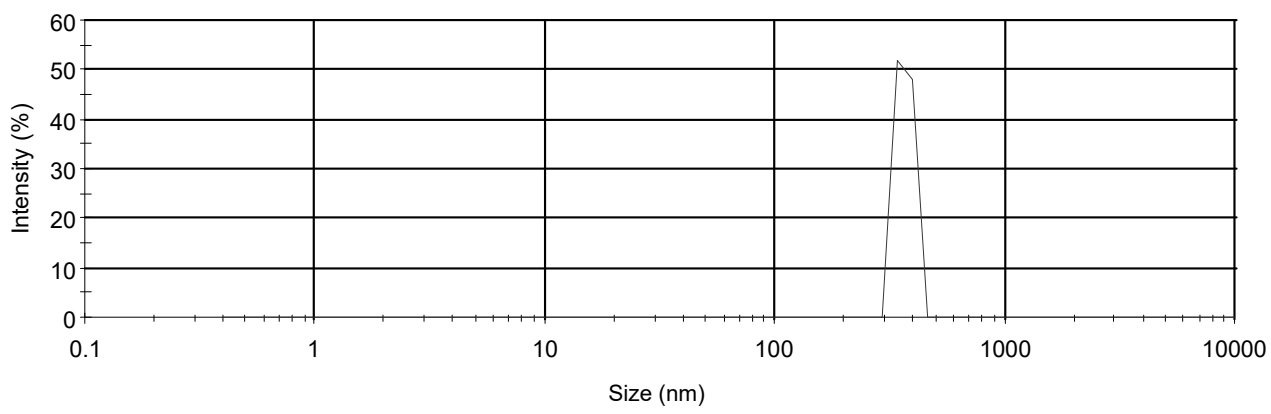

Fig. 2 Grain size distribution of T-SiC powder. 

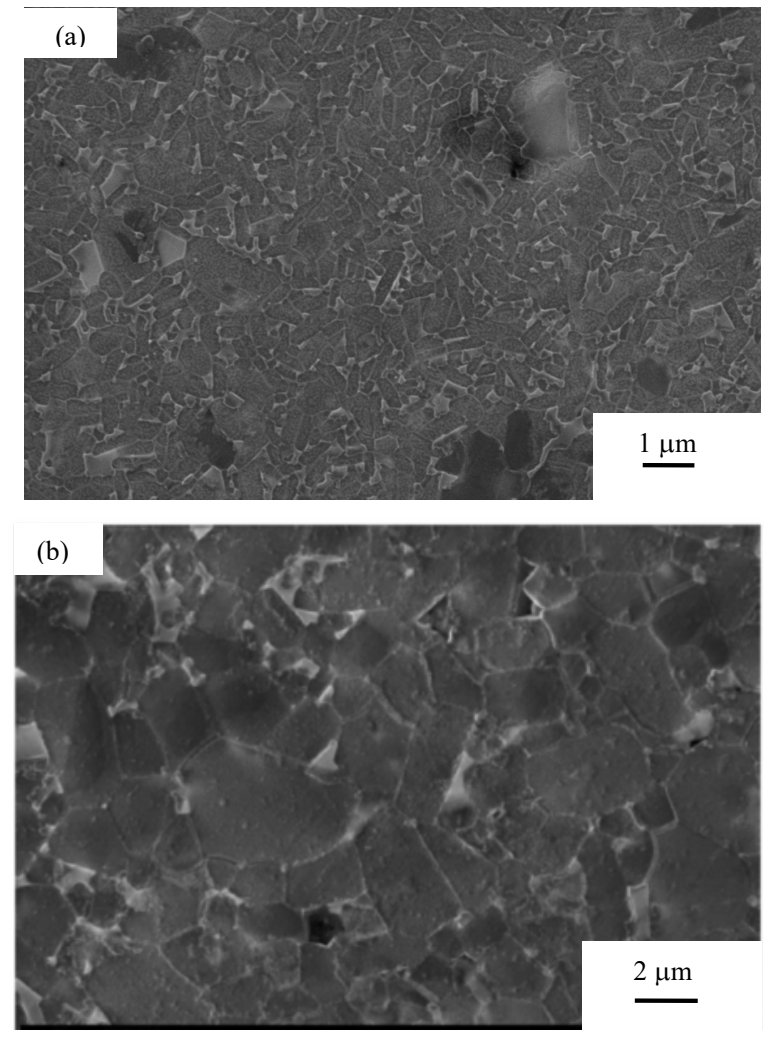

Fig. 3 Microstructure of (a) T-SiC and (b) C-SiC sintered samples.

shown in Fig. 4. These grains show the typical core-rim structure. The core presents higher $\mathrm{SiC}$ content than the rim, proving that liquid-phase sintering proceeds via solution-reprecipitation mechanism where $\mathrm{Al}_{2} \mathrm{O}_{3}-\mathrm{Y}_{2} \mathrm{O}_{3}$ additive system forms a reactive $\mathrm{Al}-\mathrm{Y}-\mathrm{O}$ rich liquid phase during densification and grain growth [28]. Furthermore, liquid phase generally appears well-distributed in both samples. The liquid phase was identified by means of XRD analysis. X-ray patterns of $\mathrm{C}-\mathrm{SiC}$ and T-SiC sintered samples are reported in Fig. 5. $\mathrm{C}$-SiC sintered sample is composed by hexagonal $\alpha$-SiC (polytypes $6 \mathrm{H}$ and $4 \mathrm{H}$ ) as main phase and yttrium

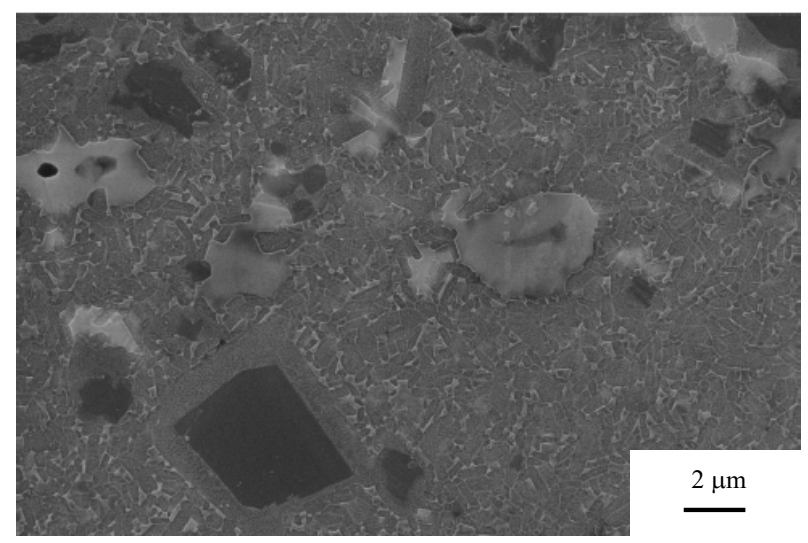

Fig. 4 Microstructural inhomogeneity in $\mathrm{T}-\mathrm{SiC}$ sintered sample.

aluminate garnet $\mathrm{YAG}\left(\mathrm{Y}_{3} \mathrm{Al}_{5} \mathrm{O}_{12}\right)$ as liquid phase. $\mathrm{T}$-SiC sintered sample shows some differences. In fact, the main phase is a mixture of cubic $\beta-\mathrm{SiC}$ (3C) and hexagonal $\alpha$-SiC $(4 \mathrm{H})$, whereas small peaks of yttrium silicide $\left(\mathrm{YSi}_{2}\right)$ and aluminum silicon carbide $\left(\mathrm{Al}_{4} \mathrm{SiC}_{4}\right)$ are identified together with peaks of $\mathrm{Y}_{3} \mathrm{Al}_{5} \mathrm{O}_{12}$. This difference can be attributed to the different amount of impurities (e.g., oxygen and free carbon) and sintering additives. $\mathrm{YSi}_{2}$ and $\mathrm{Al}_{4} \mathrm{SiC}_{4}$ are two additional liquid phases already identified in the system $\mathrm{SiC}-\mathrm{Y}_{2} \mathrm{O}_{3}-\mathrm{Al}_{2} \mathrm{O}_{3}$ by Ihle et al. [29,30]. In particular, they demonstrated that the formation of these phases is favored at $1950{ }^{\circ} \mathrm{C}$ in flowing argon due to the interaction of silicon carbide powder with additives and the carbonaceous atmosphere inside the furnace.

Mechanical properties of $\mathrm{T}-\mathrm{SiC}$ and $\mathrm{C}-\mathrm{SiC}$ sintered samples are summarized in Table 3. As a consequence of the finer microstructure at the same density, T-SiC shows higher flexural strength than $\mathrm{C}$-SiC, not only at room temperature $(508$ vs. $458 \mathrm{MPa})$ but also at $1500{ }^{\circ} \mathrm{C}$ ( 280 vs. $\left.171 \mathrm{MPa}\right)$. In Table 3, literature data reported by Kim et al. [31] is also reported with the aim
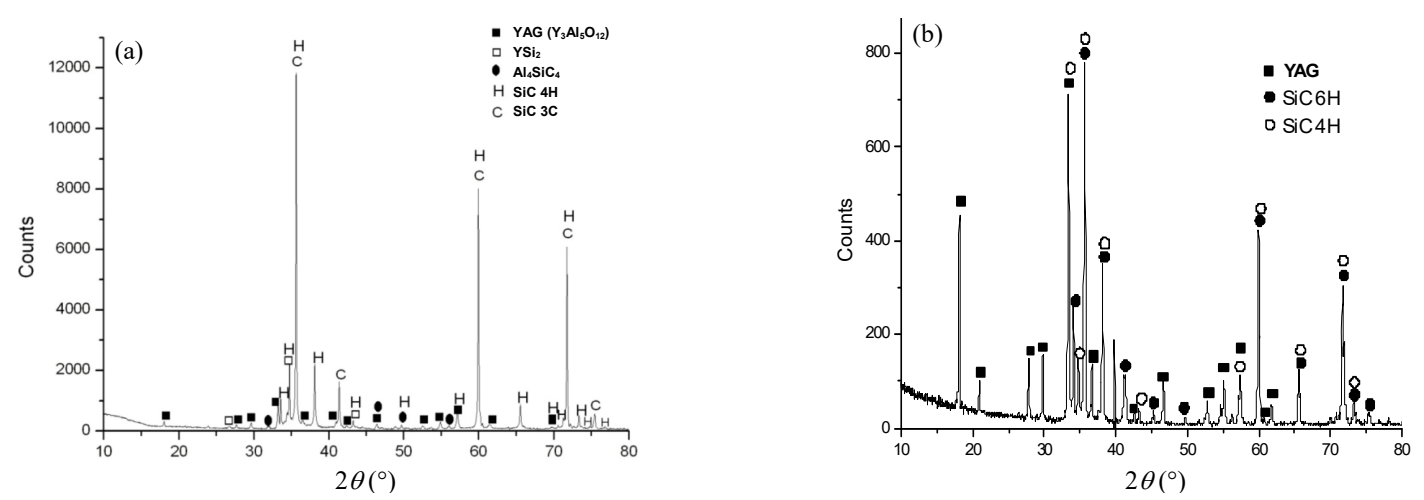

Fig. 5 XRD patterns of (a) T-SiC and (b) C-SiC sintered samples. 
Table 3 Mechanical properties of $\mathrm{T}-\mathrm{SiC}$ and $\mathrm{C}-\mathrm{SiC}$ sintered samples and the unbiased estimate of the Weibull modulus, $m_{\text {est }}$, of T-SiC

\begin{tabular}{lcccc}
\hline \multicolumn{1}{c}{ Property } & & T-SiC & C-SiC & $\begin{array}{c}\text { Kim } e t \\
\text { al. }[31]\end{array}$ \\
\hline $\begin{array}{l}\text { Flexural strength at } \\
\text { temperature (MPa) }\end{array}$ & & $508 \pm 31$ & $458 \pm 26$ & 477 \\
Flexural strength at $1300{ }^{\circ} \mathrm{C}(\mathrm{MPa})$ & $451 \pm 24$ & - & \\
Flexural strength at $1500{ }^{\circ} \mathrm{C}(\mathrm{MPa})$ & $280 \pm 19$ & $171 \pm 16$ & \\
Elastic modulus $(\mathrm{GPa})$ & & $427 \pm 2$ & $412 \pm 2$ & \\
Hardness (GPa) & $20 \pm 0.5$ & $24 \pm 0.7$ & \\
Fracture toughness $\left(\mathrm{MPa} \cdot \mathrm{m}^{1 / 2}\right)$ & $6 \pm 0.3$ & $4.5 \pm 0.2$ & 4.4 \\
Weibull modulus $m_{\mathrm{est}}$ & 14 & - & \\
\hline
\end{tabular}

to underline the high mechanical performance of T-SiC in comparison with other commercial material. High temperature resistance of liquid-phase sintered silicon carbide with alumina and yttria as additives is negatively influenced by the degradation of $\mathrm{YAG}$ with the consequent formation of the glassy phase $\gamma-\mathrm{Y}_{2} \mathrm{Si}_{2} \mathrm{O}_{7}$ as clearly demonstrated in a previous work [32]. Several studies demonstrated that improvements in high temperature resistance of liquid-phase sintered silicon carbide can be effectively achieved by using different sintering aids (e.g., $\mathrm{AlN}-\mathrm{Y}_{2} \mathrm{O}_{3}, \mathrm{AlN}-\mathrm{Lu}_{2} \mathrm{O}_{3}$ ) $[33,34]$. In the case of sintered $\mathrm{T}-\mathrm{SiC}, \mathrm{Al}_{4} \mathrm{SiC}_{4}$, crystalline phase with a well-known high oxidation resistance [35], has a beneficial effect on the high temperature resistance. The SEM images of the fracture surface of T-SiC after flexural strength tests performed at room temperature and $1500{ }^{\circ} \mathrm{C}$ are shown in Fig. 6 . At high temperature, it is evident that the effect of the liquid-phase decomposition which led to the formation of defects is responsible for the flexural strength degradation.

An estimation of the Weibull distribution of strength was also determined by the method proposed by Tiryakioğlu [36] for an unbiased estimate of the Weibull modulus for sample sizes between 9 and 50. The Weibull plot is reported in Fig. 6. The estimated Weibull modulus $\left(m_{\text {est }}\right)$ reported in Table 3 was determined by least square method of the straight line shown in Fig. 7. Because Weibull modulus reflects the reliability of brittle materials and homogeneity of the testing data, it can be preliminarily concluded that reliable, repeatable, and homogeneous ceramics could be achieved with T-SiC powder.

$\mathrm{C}-\mathrm{SiC}$ shows higher hardness than $\mathrm{T}-\mathrm{SiC}$ probably due to the absence of the soft phases like $\mathrm{YSi}_{2}$ and $\mathrm{Al}_{4} \mathrm{SiC}_{4}$. The same phases lead to an increase of the crack propagation resistance through the enhancement of the crack deflection mechanism responsible for the higher value of fracture toughness in $\mathrm{T}-\mathrm{SiC}$ than $\mathrm{C}$-SiC
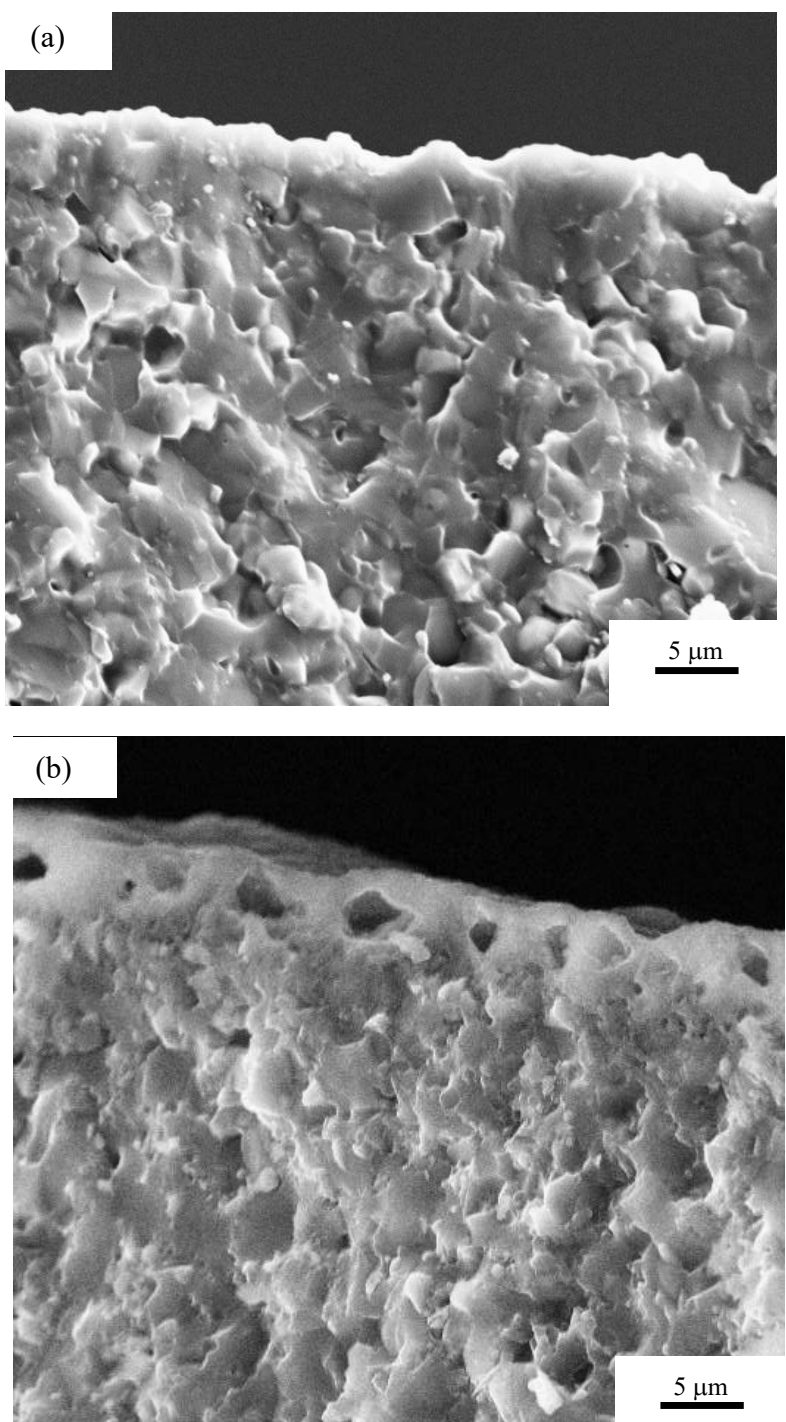

Fig. 6 Fracture surface of $\mathrm{T}-\mathrm{SiC}$ sintered sample tested at (a) room temperature and (b) $1500{ }^{\circ} \mathrm{C}$.

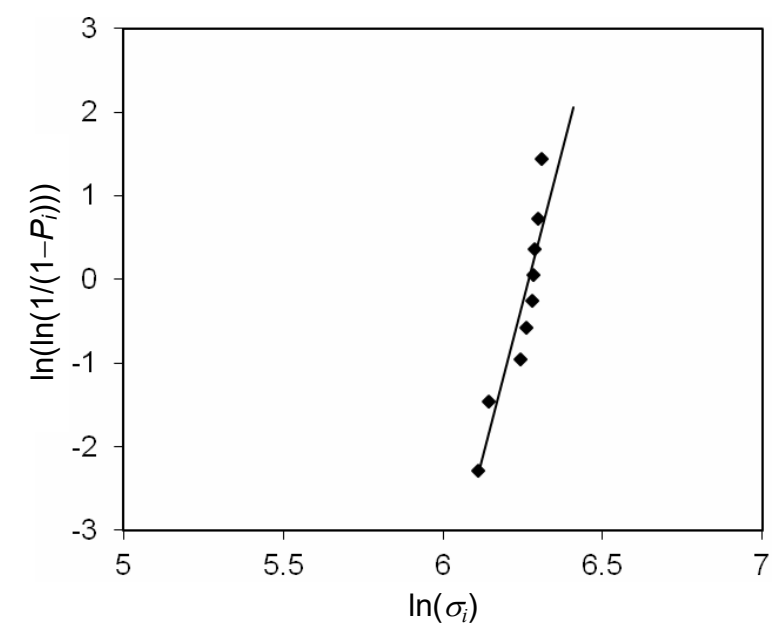

Fig. 7 Weibull plot of T-SiC material ( $\sigma_{i}=$ flexural strength, $P_{i}=$ failure probability). 
as reported in Fig. 8.

Finally, very high value of the Young's modulus for the T-SiC sample also confirms the high density obtained, considering that theoretical value of the Young's modulus of the pore free $\mathrm{SiC}$ is reported to be $460 \mathrm{GPa}$ [37].

\section{Conclusions}

SiC powder obtained from waste tires (char) was successfully pressureless sintered through liquid-phase mechanism. Comparison with pressureless sintered SiC obtained from commercial powder mainly showed higher flexural strength from room temperature to $1500{ }^{\circ} \mathrm{C}$ of the $\mathrm{T}-\mathrm{SiC}$ sintered sample. On the basis of the results of the characterization, it can be concluded that char can be seriously considered as a useful raw material for production of high quality ceramic powder.
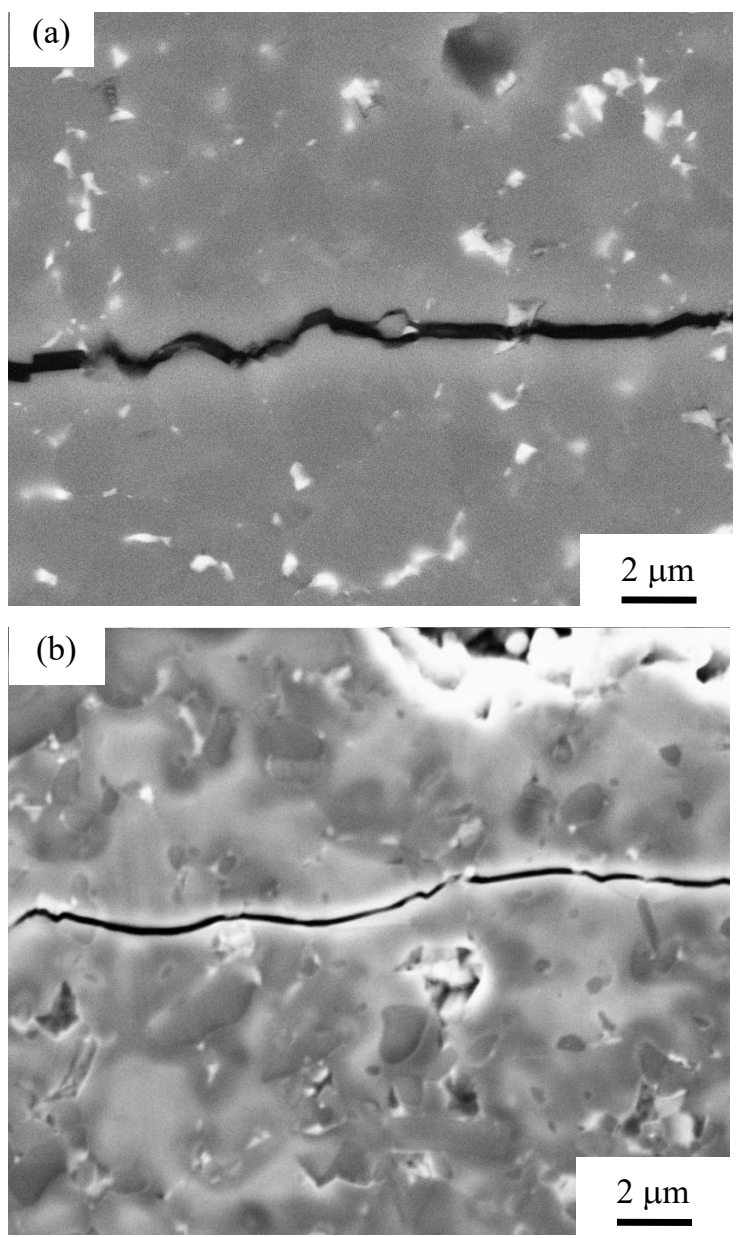

Fig. 8 Crack paths of (a) T-SiC and (b) C-SiC sintered samples.

\section{Acknowledgements}

This study was supported by the Seventh Framework Programme (FP7) 2007-2013, in the frame of the TyGRe project (Contract No. 226549). The authors wish to thank Dr. Paride Fabbri (ENEA-Faenza), Dr. Giancarlo Raiteri (ENEA-Faenza), Dr. Alida Brentari (Certimac Scarl), and Dr. Anna De Girolamo Del Mauro (ENEA-Portici) for their fruitful collaboration.

\section{References}

[1] Izhevskyi VA, Genova LA, Bressiani JC, et al. Review article: Silicon carbide. Structure, properties and processing. Cerâmica 2000, 46: 4-13.

[2] Willander M, Friesel M, Wahab Q, et al. Silicon carbide and diamond for high temperature device applications. J Mater Sci: Mater El 2006, 17: 1-25.

[3] Guichelaar PJ. Acheson process. In: Carbide, Nitride and Boride Materials Synthesis and Processing. Weimer AW, Ed. Springer Netherlands, 1997: 115-129.

[4] Martin H-P, Ecke R, Müller E. Synthesis of nanocrystalline silicon carbide powder by carbothermal reduction. $J$ Eur Ceram Soc 1998, 18: 1737-1742.

[5] Chiew YI, Cheong KY. A review on the synthesis of $\mathrm{SiC}$ from plant-based biomasses. Mat Sci Eng B 2011, 176: 951-964.

[6] Wang L, Hu X, Xu X, et al. Synthesis of high purity SiC powder for high-resistivity $\mathrm{SiC}$ single crystals growth. J Mater Sci Technol 2007, 23: 118-122.

[7] Ni J, Li Z, Zhang Z. Synthesis of silicon carbide nanowires by solid phase source chemical vapor deposition. Front Mater Sci China 2007, 1: 304-308.

[8] Yamada O, Miyamoto Y, Koizumi M. Self-propagating high-temperature synthesis of the SiC. J Mater Res 1986, 1: 275-279.

[9] Raman V, Bahl OP, Dhawan U. Synthesis of silicon carbide through the sol-gel process from different precursors. J Mater Sci 1995, 30: 2686-2693.

[10] Ramesh PD, Vaidhyanathan B, Ganguli M, et al. Synthesis of $\beta$-SiC powder by use of microwave radiation. $J$ Mater Res 1994, 9: 3025-3027.

[11] Hollabaugh CM, Hull DE, Newkirk LR, et al. R.F.-plasma system for the production of ultrafine, ultrapure silicon carbide powder. J Mater Sci 1983, 18: 3190-3194.

[12] Gitzhofer F. Induction plasma synthesis of ultrafine SiC. Pure Appl Chem 1996, 68: 1113-1120.

[13] Inoue Y, Nariki Y, Tanaka K. Mechanism of production of ultra-fine silicon carbide powder by arc plasma irradiation of silicon bulk in methane-based atmosphere. J Mater Sci 1989, 24: 3819-3823.

[14] Guo JY, Gitzhofer F, Boulos MI. Induction plasma synthesis of ultrafine $\mathrm{SiC}$ powders from silicon and $\mathrm{CH}_{4}$. J Mater Sci 1995, 30: 5589-5599.

[15] Zhu CW, Zhao GY, Revankar V, et al. Synthesis of ultra-fine $\mathrm{SiC}$ powders in a d.c. plasma reactor. J Mater $S c i$ 
1993, 28: 659-668.

[16] Kong PC, Pfender E. Formation of ultrafine $\beta$-silicon carbide powders in an argon thermal plasma jet. Langmuir 1987, 3: 259-265.

[17] Lee HJ, Eguchi K, Yoshida T. Preparation of ultrafine silicon nitride, and silicon nitride and silicon carbide mixed powders in a hybrid plasma. J Am Ceram Soc 1990, 73: 3356-3362.

[18] Ko S-M, Koo S-M, Cho W-S, et al. Synthesis of SiC nano-powder from organic precursors using RF inductively coupled thermal plasma. Ceram Int 2012, 38: 1959-1963.

[19] Leconte Y, Leparoux M, Portier X, et al. Controlled synthesis of $\beta$-SiC nanopowders with variable stoichiometry using inductively coupled plasma. Plasma Chem Plasma Process 2008, 28: 233-248.

[20] Singh SK, Stachowicz L, Girshick SL, et al. Plasma synthesis of $\mathrm{SiC}$ from rice hull (husk). J Mater Sci Lett 1993, 12: 659-660.

[21] Maity A, Kalita D, Kayal TK, et al. Synthesis of SiC ceramics from processed cellulosic bio-precursor. Ceram Int 2010, 36: 323-331.

[22] Yukhymchuk VO, Kiselev VS, Belyaev AE, et al. Synthesis, morphological and properties of bio-SiC ceramics. Funct Mater 2010, 17: 520-527.

[23] Galvagno S, Portofino S, Casciaro G, et al. Synthesis of beta silicon carbide powders from biomass gasification residue. J Mater Sci 2007, 42: 6878-6886.

[24] Károly Z, Mohai I, Klébert Sz, et al. Synthesis of SiC powder by RF plasma technique. Powder Technol 2011, 214: 300-305.

[25] Galvagno S, Portofino S, Freda C, et al. Metodo di purificazione da metalli per la preparazione di composti ceramici ad elevata purezza. Italian patent RM2013A000277, 2013.

[26] Niihara K, Nakahira A, Hirai T. The effect of stoichiometry on mechanical properties of boron carbide. J Am Ceram Soc 1984, 67: C-13-C-14.

[27] Baud S, Thévenot F, Pisch A, et al. High temperature sintering of $\mathrm{SiC}$ with oxide additives: I. Analysis in the $\mathrm{SiC}-\mathrm{Al}_{2} \mathrm{O}_{3}$ and $\mathrm{SiC}-\mathrm{Al}_{2} \mathrm{O}_{3}-\mathrm{Y}_{2} \mathrm{O}_{3}$ systems. $J$ Eur Ceram Soc 2003, 23: 1-8.

[28] Sigl LS, Kleebe H-J. Core/rim structure of liquid-phase-sintered silicon carbide. $J$ Am Ceram Soc 1993, 76: 773-776.

[29] Ihle J, Herrmann M, Adler J. Phase formation in porous liquid phase sintered silicon carbide: Part I: Interaction between $\mathrm{Al}_{2} \mathrm{O}_{3}$ and SiC. $J$ Eur Ceram Soc 2005, 25: 987-995.

[30] Ihle J, Herrmann M, Adler J. Phase formation in porous liquid phase sintered silicon carbide: Part II: Interaction between $\mathrm{Y}_{2} \mathrm{O}_{3}$ and SiC. $J$ Eur Ceram Soc 2005, 25: 997-1003.

[31] Kim Y-M, Mitomo M, Emoto H, et al. Effect of initial $\alpha$-phase content on microstructure and mechanical properties of sintered silicon carbide. J Am Ceram Soc 1998, 81: 3136-3140.

[32] Magnani G, Minoccari GL, Pilotti L. Flexural strength and toughness of liquid phase sintered silicon carbide. Ceram Int 2000, 26: 495-500.

[33] Keppeler M, Reichert HG, Broadley JM, et al. High temperature mechanical behaviour of liquid phase sintered silicon carbide. J Eur Ceram Soc 1998, 18: 521-526.

[34] Lim K-Y, Kim Y-W, Nishimura T, et al. High temperature strength of silicon carbide sintered with $1 \mathrm{wt} . \%$ aluminum nitride and lutetium oxide. J Eur Ceram Soc 2013, 33: 345-350.

[35] Huang X, Wen G. Mechanical properties of $\mathrm{Al}_{4} \mathrm{SiC}_{4}$ bulk ceramics produced by solid state reaction. Ceram Int 2007, 33: 453-458.

[36] Tiryakioğlu M. An unbiased probability estimator to determine Weibull modulus by the linear regression method. J Mater Sci 2006, 41: 5011-5013

[37] Snead LL, Nozawa T, Katoh Y, et al. Handbook of SiC properties for fuel performance modeling. J Nucl Mater 2007, 371: 329-377.

Open Access The articles published in this journal are distributed under the terms of the Creative Commons Attribution 4.0 International License (http://creativecommons.org/licenses/ by/4.0/), which permits unrestricted use, distribution, and reproduction in any medium, provided you give appropriate credit to the original author(s) and the source, provide a link to the Creative Commons license, and indicate if changes were made. 